\title{
Structure and properties of aluminium-magnesium casting alloys after heat treatment
}

\author{
Mariusz Król $\mathbf{1}^{1}$ - Tomasz Tański ${ }^{1}$ Przemysław Snopiński ${ }^{1}$. \\ Błażej Tomiczek ${ }^{1}$
}

Received: 10 December 2015/Accepted: 11 September 2016/Published online: 21 September 2016

(c) The Author(s) 2016. This article is published with open access at Springerlink.com

\begin{abstract}
Since the forming of the microstructure depends on the specific of the casting method, which directly affects further mechanical and physical properties of the material, it is important to understand how to control the microstructure of the cast to understand changes that taking place during the crystallisation process. For estimating the metallurgical quality of the liquid metal before casting, the thermal-derivative analysis (TDA) is utilised. The TDA has been used for a long time, in both ferrous and non-ferrous industries casting. The Universal Metallurgical Simulator and Analyser (UMSA) platform is a rapid, sensitive and economical method of determining a full range of solidification features. The work focuses on the thermal analysis and heat treatment of aluminium alloys. The liquidus and solidus temperatures and dendrite coherency point (DCP) are then characterised. The research shows that the UMSA platform allows precise determination and calculation of thermal parameters. The influence of the heat treatment on structure and properties of aluminium castings has been determined as well. Heat treatment was carried out to increase the mechanical properties of aluminium alloys.
\end{abstract}

Mariusz Król

mariusz.krol@polsl.pl

Tomasz Tański

tomasz.tanski@polsl.pl

Przemysław Snopiński

przemyslaw.snopinski@polsl.pl

Błażej Tomiczek

blazej.tomiczek@polsl.pl

1 Faculty of Mechanical Engineering, Institute of Engineering Materials and Biomaterials, Silesian University of Technology, Konarskiego 18a St., 44-100 Gliwice, Poland
Based on the findings above, the influence of microstructure on properties of the alloys is discussed.

Keywords Thermal-derivative analysis - Dendrite coherency point $\cdot$ Heat treatment $\cdot$ Structure $\cdot$ Aluminium alloy $\cdot$ Tensile properties

\section{Introduction}

Aluminium-magnesium casting alloys have a wide range of application, especially in the automotive and shipborne industry that is directly related to their good mechanical properties $[1,2]$. These alloys are characterised by relatively good castability and are distinguished by excellent corrosion resistance due to high magnesium content [3, 4]. However, application of aluminium casting alloys for structural components requires high strength and suitable high elongations. Grain size, their morphology, interdendritic distance and distribution of secondary phases are crucial factors affecting mechanical properties of cast parts [1, 5-7]. The quality of the microstructure of aluminium alloys mainly depends on the chemical composition, melting process and cooling rate [7-9]. Due to those facts, it is important to understand how to control structure forming of aluminium alloys through casting or heat treatment.

The grain size of alloys related closely to their solidification characteristics under equilibrium and non-equilibrium conditions. Due to its comfort of use and inexpensive cost, thermal-derivative analysis (TDA) is much more suitable for industrial applications related to other thermal techniques and TDA method has been successfully used to analyse the features of aluminium, magnesium and zinc alloys in recent years [10-12]. In this method, the 
temperature changes in the sample are recorded from wholly liquid to completely solidified phases creating a curve plot of temperature as a function of time. A cooling curve reflects the release of latent heat of solidification. This release of latent heat in multicomponent alloys changes the slope of the cooling curve which is then used to detect the characteristics of transitions and phase reactions during solidification [11-13]. The solidification characteristics, e.g., dendrite nucleation and dendrite coherency, can be derived from thermal analysis of the alloy solidification. The dendrite coherency point temperature refers to the state of solidifying alloys at which a coherent dendrite network is established through the formation of grains. Once the dendrites become coherent, liquid metal flow is restricted to interdendritic regions. There exist four main DCP temperature testing approaches: the rheological technique (however, this method may influence DCP measurement), thermal analysis of the minimum temperature differences between two cooling curves, thermal analysis of the second derivative of cooling curve and the thermal diffusivity measurements techniques $[12,14]$.

The dendrite coherency point (DCP) temperature refers to the state of a solidifying alloy at which a coherent dendrite network is established during the formation of grains. In agreement with this understanding, the grain size in solidifying microstructure has been decided and will not change at/after this point. Correspondingly, the solid fraction $(f)$ at $\mathrm{DCP}$ has been defined as $f_{\mathrm{DCP}}$, and a higher $f_{\mathrm{DCP}}$ means finer grain size after solidification of alloy [14].

Specialists have been working for many years to improve mechanical properties of light alloys through the microstructure controlling using special casting techniques (sand casting, high-pressure die casting, mould casting), adding micro-additions that cause obtaining fine-grained microstructure, applying surface treatments or using heat treatment that should ensure increase in material properties [15-17].

The effect of precipitation treatment on the structure forming and mechanical properties of $\mathrm{Al}-\mathrm{Mg}$ binary alloys in recent years has been very precisely investigated. Scientist described precipitation sequence accurately during artificial ageing of aluminium-magnesium alloys and proposed sequence:

$\operatorname{sss} \alpha \rightarrow$ GP zones $\rightarrow \beta^{\prime} \rightarrow \beta^{\prime \prime} \rightarrow \beta$

where supersaturated solid solution is sss $\alpha$, GP forming of Guinier-Preston zones, $\beta^{\prime \prime}$ is an $\mathrm{L1}_{2}\left(\mathrm{Al}_{3} \mathrm{Mg}\right)$ and $\beta^{\prime}$ forming of phase $\mathrm{Al}_{3} \mathrm{Mg}_{2}$, which directly increases mechanical properties of $\mathrm{Al}-\mathrm{Mg}$ alloys. It was also found that when $\mathrm{Al}-\mathrm{Mg}$ alloy with $<18 \% \mathrm{Mg}$ content is aged at a temperature between 100 and $250{ }^{\circ} \mathrm{C}$, the $\beta^{\prime}$ forms first and the presence of $\beta$ phase could be observed only when $\mathrm{Mg}$ depletion of the matrix is almost complete $[9,18]$.

The presented investigation was initiated to determine an influence of heat treatment on the structure and properties of EN AC 51100 and EN AC 51300 alloys. The first stage of the experiment was to examine the influence of cooling rate on the solidification process in studied alloys. The second stage was determination of the most beneficial type of heat treatment based on the mechanical examinations such as hardness measurements and static tensile test.

\section{Experimental}

\section{Material}

The investigation has been carried out on commercial aluminium alloy-appointed by the standard EN 1706:2010 (51100 and 51300). Because of high magnesium content, these alloys are characterised by high corrosion resistance and relatively high strength. The chemical composition of the alloys is given in Table 1.

\section{Metallographic investigations}

The metallographic studies of EN AC 51100 and EN AC 51300 alloys were made on the as-cast samples taken from the ingot and on samples after solution treatment and artificial ageing. The change of the microstructure of samples subjected to different types of heat treatment has been investigated. Specimens were cold mounted and ground on 240\#, 320\#, 400\#, 600\# and 1200\# SiC abrasive and then finished with 6-, 3- and 1- $\mu \mathrm{m}$ diamond paste. To reveal microstructure prepared specimens were etched using Keller's reagent $(0.5 \mathrm{~mL} \mathrm{HF}, 1.5 \mathrm{~mL} \mathrm{HCl}, 2.5 \mathrm{~mL}$ $\left.\mathrm{HNO}_{3}, 95.5 \mathrm{~mL} \mathrm{H}_{2} \mathrm{O}\right)$ and Weck's reagent $\left(4 \mathrm{~g} \mathrm{KMnO}_{4}\right.$, $1 \mathrm{~g} \mathrm{NaOH}, 100 \mathrm{~mL} \mathrm{H}_{2} \mathrm{O}$ ) immersed for $60 \mathrm{~s}$. To obtain grain contrast, the polished samples were subjected to electrolytic etching using Barker's reagent $(5 \mathrm{~mL}$ HBF4 (40\%), $200 \mathrm{~mL} \mathrm{H}_{2} \mathrm{O}$ ) under a current of $20 \mathrm{~V}$ and then observed under bright field and polarised light (using sensitive tint). The microstructure of characteristic states of investigated alloy was observed using an optical microscope Axio Observer Image Analyser.

Table 1 Chemical composition of investigated alloys/mass/\%

\begin{tabular}{llllll}
\hline & $\mathrm{Mg}$ & $\mathrm{Si}$ & $\mathrm{Fe}$ & $\mathrm{Cu}$ & $\mathrm{Al}$ \\
\hline EN AC 51100 & 2.86 & 0.07 & 0.07 & 0.01 & $\mathrm{Bal}$ \\
EN AC 51300 & 5.55 & 0.08 & 0.07 & 0.01 & $\mathrm{Bal}$ \\
\hline
\end{tabular}



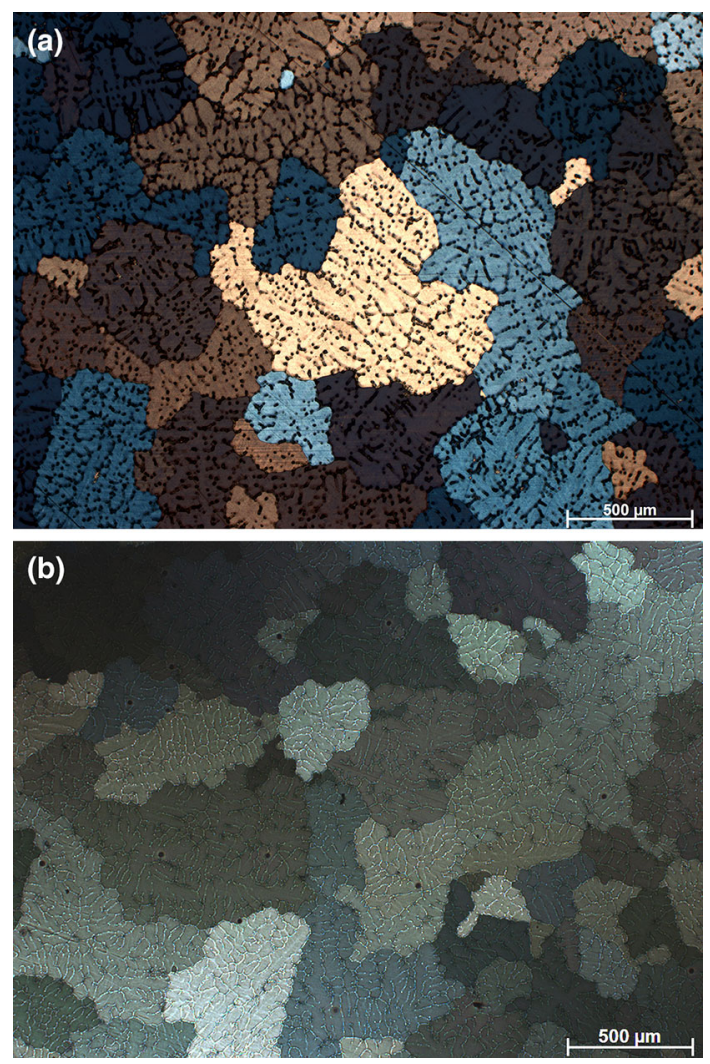

Fig. 1 Microstructure of a EN AC 51100, b EN AC 51300 alloy in as-cast condition observed in polarised light

\section{Thermal analysis}

The thermal analysis through melting and solidification sequences was performed using the Universal Metallurgical Simulator and Analyser (UMSA) [13]. The melting and solidification trails for the aluminium alloy were performed using argon as cover gas. The data for thermal analysis (TA) was gathered using a high-speed National Instruments data acquisition system linked to a personal computer. The recorded data were imported into Fityk for data analysis. The cooling curves and corresponding derivative curves were plotted to determine characteristic thermal events, based on the first and second derivative of cooling curve. To ensure the reproducibility of testing results, a thermal analysis of each alloy was performed at least three times. The procedure consisted of following steps. First, the test specimen was heated to $700 \pm 2{ }^{\circ} \mathrm{C}$ and isothermally held at this temperature for $90 \mathrm{~s}$ to stabilise the melt conditions. Next, the test sample was solidified at a cooling rate of approximately 0.5 and $0.9^{\circ} \mathrm{C} \mathrm{s}^{-1}$ that was equivalent to the solidification process under natural and accelerated cooling conditions.

For the determination of solid fraction at DCP, the Newtonian baseline has been estimated by sixth
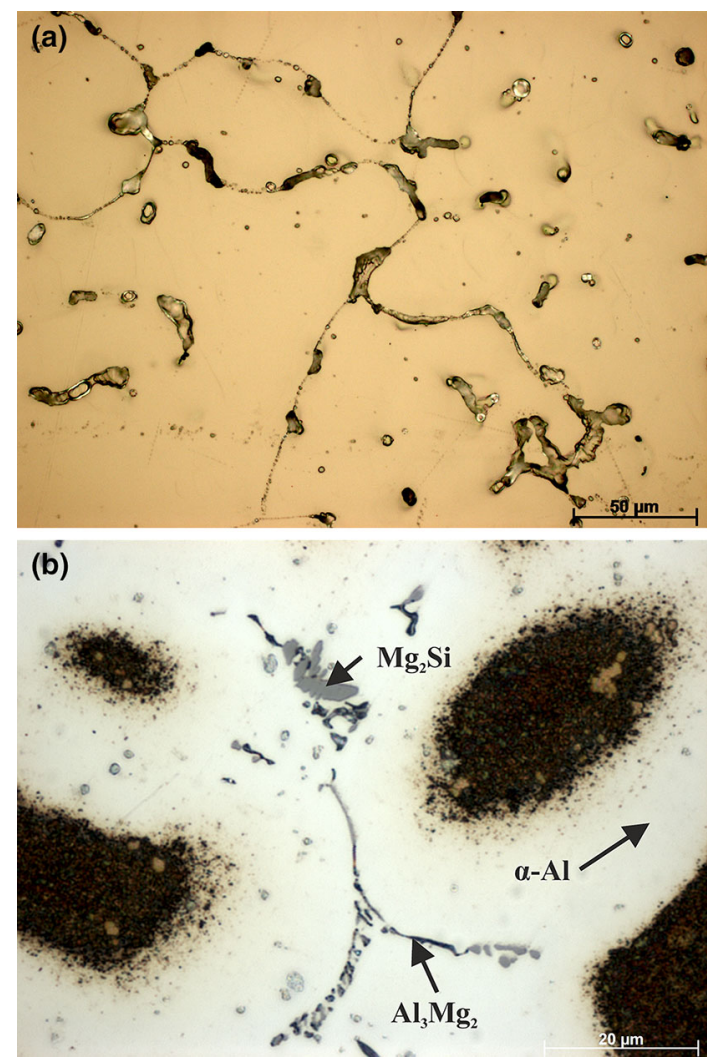

Fig. 2 Microstructure of EN AC 51100 in as-cast condition a etched using Keller's reagent, b etched using Weck's reagent (bright field)

polynomial fitting $\quad(\mathrm{d} T / \mathrm{d} t)_{\mathrm{BL}}=a_{0}+a_{1} T+a_{2} T^{2}+$ $a_{3} T^{3}+a_{4} T^{4}+a_{5} T^{5}+a_{6} T^{6}$ between the beginning and the end of solidification in the first derivative curve. The sixth-order polynomial yields a correlation coefficient $>0.99$. The solid fraction at DCP was calculated from the accumulative area between the first derivative and the baseline at $t_{\mathrm{DCP}}$ as a fraction of the area between these curves.

\section{Heat treatment}

The solid solution temperature of EN AC 51100 and EN AC 51300 alloy was selected experimentally and based on the results obtained from the thermal-derivative analysis (UMSA). The test samples were heated for 8 and $12 \mathrm{~h}$ in the furnace in a wide range of temperatures and then immediately cooled in cold water. The influence of solid solution hardening and the artificial ageing mechanism of EN AC 51100 and EN AC 51300 alloys was precisely investigated. The temperature of artificial ageing was $160{ }^{\circ} \mathrm{C}$. To analyse the influence of ageing time on the ageing potential of studied alloys hardness and tensile test measurements were taken. 

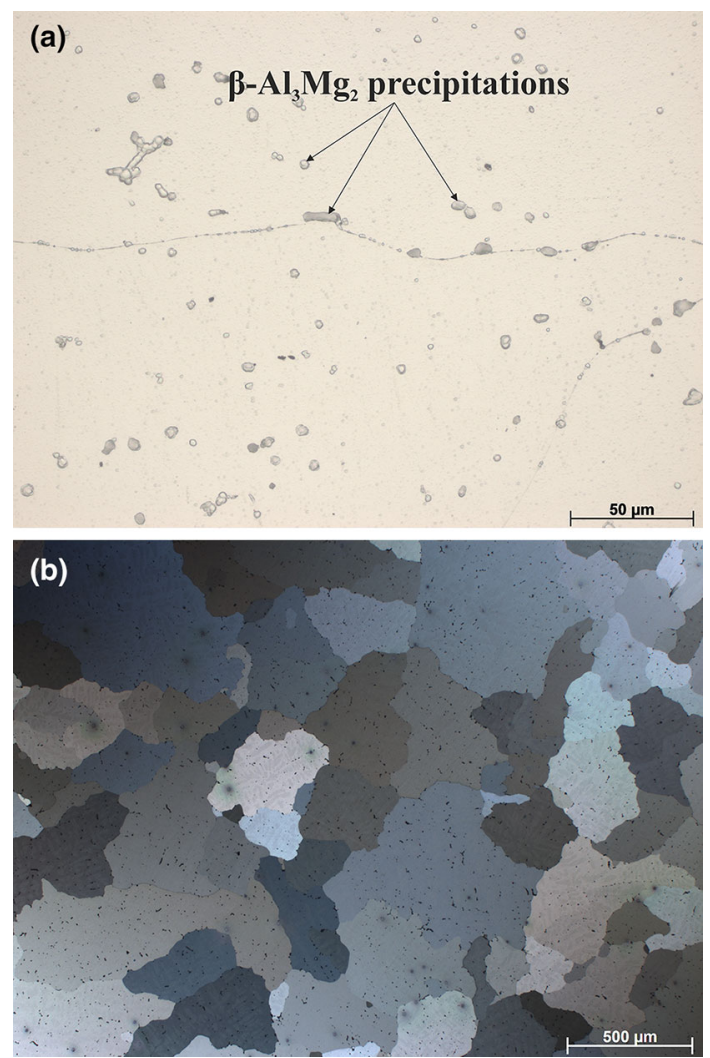

Fig. 3 Microstructure of $\mathrm{AlMg} 3$ alloy after precipitation treatment observed under a bright field (Keller's reagent), b polarised light (Barker's reagent)

\section{Mechanical properties}

To determine mechanical properties of the examined alloys, the test pieces were deformed in a static tensile test using universal tensile testing machine ZWICK Z/100 according to standard PN-EN 10002-1:2004. The hardness was measured using Automatic Rockwell hardness tester ZWICK ZHR 4150 under a load of $60 \mathrm{~kg}$. Tensile tests and hardness measurements were carried out on the as-cast samples, after solution treatment and after various numbers of artificially aged specimens. To obtain precise results, ten hardness measurements were taken on each sample.

\section{Results and discussion}

\section{Structure}

The representative grain structures of the $\mathrm{Al}-\mathrm{Mg}$ alloys in the as-received state with different $\mathrm{Mg}$ contents are presented in Fig. 1. It is clear that both samples characterise a similar equiaxed dendritic structure. In addition to the rosette-like primary $\mathrm{Al}$, there is $\beta$ phase distributed in the
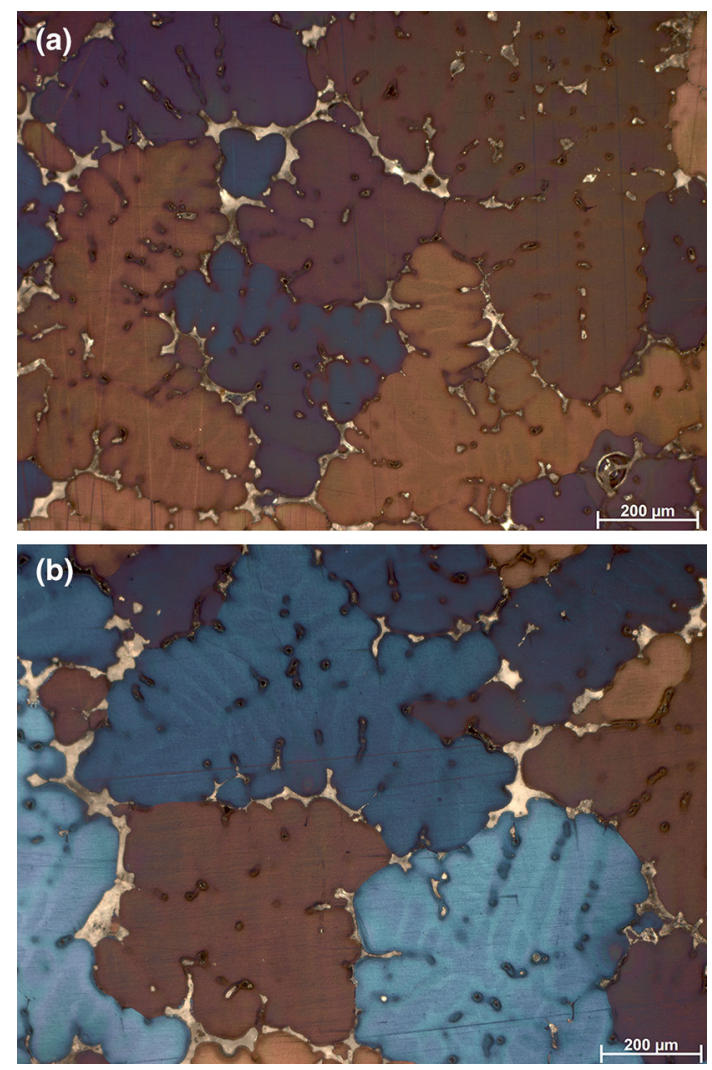

Fig. 4 Representative microstructure of the EN AC 51300 alloy after thermal analysis at cooling rate a $0.5{ }^{\circ} \mathrm{C} \mathrm{s}^{-1}, \mathbf{b ~} 0.9^{\circ} \mathrm{C} \mathrm{s}^{-1}$

interdendritic region as a result of non-equilibrium solidification. To perform precise phase identification of as-received state material, two types of etchants were used to reveal a microstructure. Keller's reagent (Fig. 2a) that is commonly used for etching of aluminium alloys revealed the secondary precipitates on the grain boundaries, but does not allow a clear distinction of structure constituents. Application of Weck's reagent allows distinguishing individual precipitations by its shade. Thus, it can be stated that the microstructure in the as-received state consists of three phases: $\alpha$ - $\mathrm{Al}$ (bright matrix), $\mathrm{Al}_{3} \mathrm{Mg}_{2}$ (dark precipitations) and $\mathrm{Mg}_{2} \mathrm{Si}$ (grey precipitations) which forms near grain boundaries (Fig. 2b). The presence of main phases has been confirmed in the previous study [21]. Precipitation treatment leads to the disappearance of dendritic structure and has no significant impact on the grain size and their morphology (Fig. 3). It is clear that during the precipitation treatment process from supersaturated solid solution precipitate the hardening secondary phases $\beta^{\prime}-\mathrm{Al}_{3} \mathrm{Mg}_{2}$ which are uniformly distributed in the matrix of the alloy. This effect has been widely studied by Starink and Zahra [16]. Figure $4 a, b$ shows the microstructures of EN AC 51300 alloy after thermal analysis. One can see that the dendrite arm spacing (DAS) and grain size increased after thermal 
analysis in comparison with as-received or heat-treated state. It can also be seen that the majority of secondary phases are located on the grain boundaries and are visible as bright precipitations. It should also be mentioned that an increase in cooling rate decreases the grain size in the case of both examined alloys. The results of the grain size measurement using line intersection method are presented in Table 2. It can also be concluded that the greater amount of magnesium in the EN AC 51300 alloy results in the smaller grain size after thermal analysis. This phenomenon can be explained by earlier nucleation of the primary phase of the alloy containing $\sim 5 \%$ of $\mathrm{Mg}$.

\section{Thermal analysis}

Before starting to analyse the solidification path of aluminium alloy must be noted that the number of phases in the as-cast state (non-equilibrium) can be larger than the number under equilibrium conditions, but the sequence of solidification reactions is, in general, in agreement with the corresponding phase diagrams.

The $\mathrm{Mg}_{2} \mathrm{Si}$ phase widely determines the properties of examined aluminium alloys, so their interpretation should be started from the $\mathrm{Al}-\mathrm{Mg}-\mathrm{Si}$ phase diagram that is relatively simple and has been treated in the literature in sufficient detail. In the aluminium corner of the $\mathrm{Al}-\mathrm{Mg}-\mathrm{Si}$ system, the following phases are in equilibrium with the aluminium solid solution: $\mathrm{Al}_{3} \mathrm{Mg}_{2}$ and $\mathrm{Mg}_{2} \mathrm{Si}$. The $\mathrm{Al}_{3} \mathrm{Mg}_{2}$ (sometimes designated as $\mathrm{Al}_{8} \mathrm{Mg}_{5}$ ) has an FCC structure with lattice parameter $a=2.82-2.86 \mathrm{~nm}$. The $\mathrm{Mg}_{2} \mathrm{Si}$ phase has a cubic structure with lattice parameter $a=0.635-0.640$. In almost all commercial alloys belonging to the $\mathrm{Al}-\mathrm{Mg}-\mathrm{Mg}_{2} \mathrm{Si}$ system, aluminium is primarily solidified, and then one of the binary eutectics is formed. The binary and ternary eutectics, involving the $\mathrm{Al}_{3} \mathrm{Mg}_{2}$ phase, can solidify in commercial alloys, only under non-equilibrium conditions. As presented in work [19], the $\mathrm{Al}_{3} \mathrm{Mg}_{2}$ phase is formed by precipitation from the aluminium solid solution upon cooling in the solid state; however, under real, non-equilibrium conditions, this phase can form during solidification as a result of eutectic reactions. In as-cast $\mathrm{Al}-\mathrm{Si}$ alloys, the $\mathrm{Mg}_{2} \mathrm{Si}$ phase develops only as a result of non-equilibrium ternary eutectic result at

Table 2 Results of grain size measurement of examined aluminium alloy after precipitation treatment

\begin{tabular}{lll}
\hline Investigated alloys & Cooling rate $/{ }^{\circ} \mathrm{C} \mathrm{s}^{-1}$ & Average grain size $/ \mu \mathrm{m}$ \\
\hline EN AC 51100 & 0.5 & 577 \\
& 0.9 & 483 \\
EN AC 51300 & 0.5 & 565 \\
& 0.9 & 464 \\
\hline
\end{tabular}
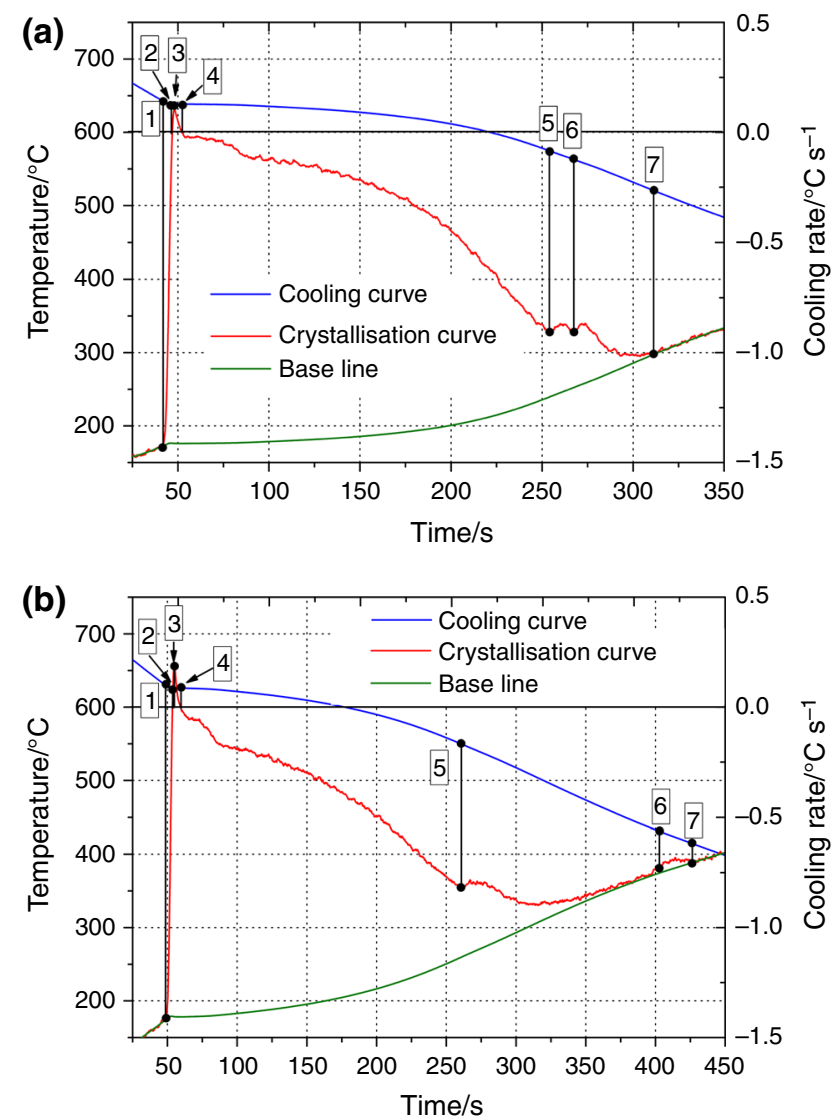

Fig. 5 Representative cooling, crystallisation and base curves with characteristic points of crystallisation process of a EN AC 51100, b EN AC 51300 aluminium alloys solidified at $0.5^{\circ} \mathrm{C} \mathrm{s}^{-1}$

$555^{\circ} \mathrm{C}$, and its amount is small $(<1$ vol.\%), which makes its classification difficult in an optical microscope. In spite of the comparatively weak mutual solubility of $\mathrm{Mg}$ and $\mathrm{Si}$ in solid $\mathrm{Al}$, it enables a significant effect of precipitation due to the formation of metastable coherent and semi-coherent modifications $\left(\beta^{\prime \prime}, \beta^{\prime}\right)$ of the $\mathrm{Mg}_{2} \mathrm{Si}$ phase during ageing. Recent results showed that the mutual solid solubility of magnesium and silicon in aluminium fully depends on temperature, which requires strict remark of a heat treatment regime. In $\mathrm{Al}-\mathrm{Mg}$ alloys containing more than $3-4 \% \mathrm{Mg}$, no secondary precipitates of $\mathrm{Mg}_{2} \mathrm{Si}$ phase are formed due to the low solubility of $\mathrm{Si}$ in $\mathrm{Al}$. Almost all silicon is bound in eutectic $\mathrm{Mg}_{2} \mathrm{Si}$ particles [19-21].

Thermal analysis results of investigated aluminium alloys have been presented in Fig. 5. More detailed information related to the alloy's thermal characteristics was obtained using first derivative curves. The temperatures of the metallurgical reactions are summarised in Table 3. The characteristic point of the thermal changes occurred during the crystallisation process defined as the point of intersection of the tangent at the inflection point of the curve 
Table 3 Non-equilibrium thermal characteristics of the EN AC 51100 and EN AC 51300 alloy test specimens obtained during solidification process at 0.5 and $0.9^{\circ} \mathrm{C} \mathrm{s}^{-1}$ solidification rates

\begin{tabular}{|c|c|c|c|c|c|}
\hline Point & Reaction & EN AC $511000.5 /{ }^{\circ} \mathrm{C} \mathrm{s}^{-1}$ & EN AC $511000.9 /{ }^{\circ} \mathrm{C} \mathrm{s}^{-1}$ & EN AC $513000.5 /{ }^{\circ} \mathrm{C} \mathrm{s}^{-1}$ & EN AC $513000.9 /{ }^{\circ} \mathrm{C} \mathrm{s}^{-1}$ \\
\hline 1 & $T_{\mathrm{NUC}}^{\alpha \mathrm{DEN}}$ & 641.3 & 639.8 & 629.1 & 633.2 \\
\hline 2 & $T_{\mathrm{MIN}}^{\alpha \mathrm{DEN}}$ & 638.0 & 637.1 & 625.2 & 623.0 \\
\hline 3 & $T_{\mathrm{DCP}}^{\alpha \mathrm{DEN}}$ & 638.5 & 637.7 & 625.9 & 623.8 \\
\hline 4 & $T_{\mathrm{G}}^{\alpha \mathrm{DEN}}$ & 638.8 & 638.2 & 626.5 & 624.1 \\
\hline 5 & $T_{\mathrm{E}\left(\mathrm{Al}+\mathrm{Mg}_{2} \mathrm{Si}\right)}$ & 574.8 & 571.1 & 550.7 & 544.7 \\
\hline 6 & $T_{\mathrm{E}\left(\mathrm{Al}+\mathrm{Al}_{3} \mathrm{Mg}_{2}\right)}$ & 563.1 & 561.1 & 436.3 & 435.2 \\
\hline 7 & $T_{\text {sol }}$ & 520.1 & 509.5 & 416.7 & 411.8 \\
\hline
\end{tabular}
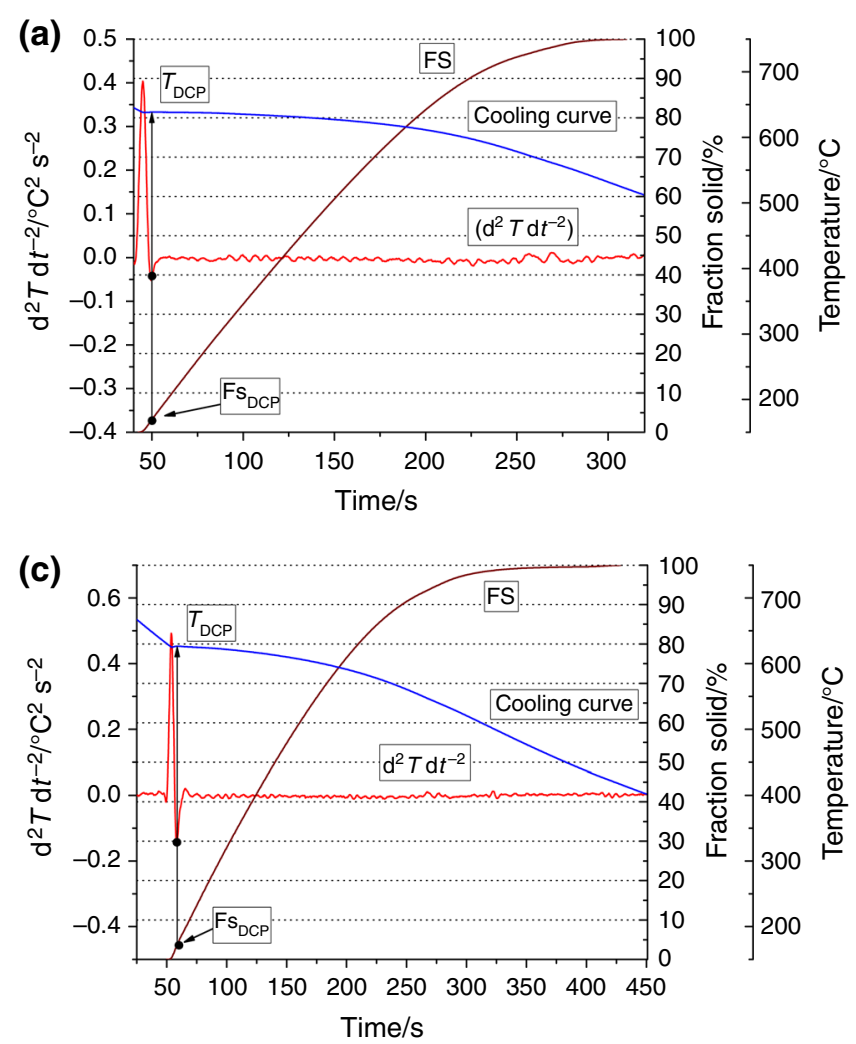
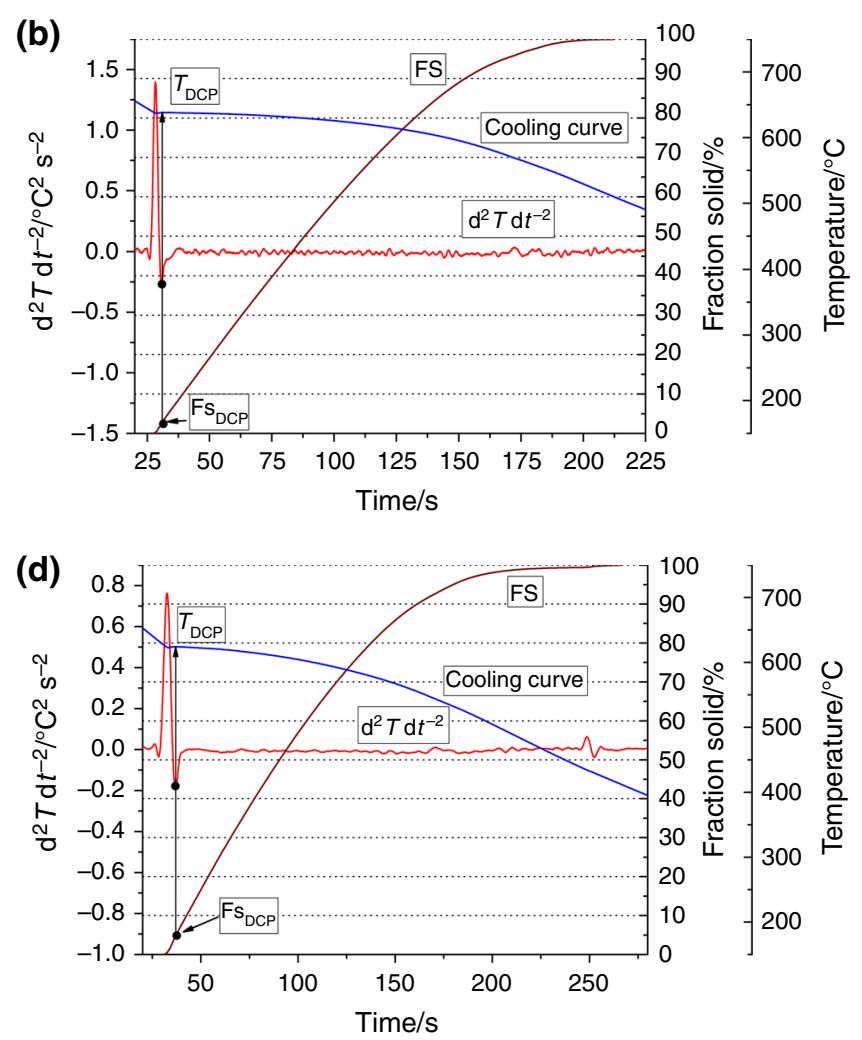

Fig. 6 Representative cooling and second derivative curves and associated fraction solid curve of the EN AC 51100 alloy solidified at a $0.5^{\circ} \mathrm{C} \mathrm{s}^{-1}, \mathrm{~b} 0.9^{\circ} \mathrm{C} \mathrm{s}^{-1}$ and the EN AC 51300 alloy solidified at $\mathbf{c} 0.5^{\circ} \mathrm{C} \mathrm{s}^{-1}, \mathbf{d ~} 0.9^{\circ} \mathrm{C} \mathrm{s}^{-1}$

with the base curve, or as a point obtained by extrapolation of the straight sections in the expression thermal analysis.

Solidification starts at approx. $629-641^{\circ} \mathrm{C}$ with the formation of aluminium grains. The $\alpha$-Al dendrite nucleation temperature $\left(T_{\mathrm{NUC}}^{\alpha \mathrm{DEN}}\right.$ ) (point 1 ) represents the point when the stable primary dendrites begin to solidify from the melt. The variation demonstrated this fact in the slope of the cooling curves and determined by the first derivative inflexion point. The liquidus temperature means the beginning of the fraction solid that, at this point, is equal to zero. Clearly, the nucleation event for $\mathrm{Al}$ dendrite takes place at higher temperatures with the lower content of magnesium in the alloy, i.e., $T_{\mathrm{NUC}}^{\alpha \mathrm{DEN}}$ was $641.3{ }^{\circ} \mathrm{C}$ for $\mathrm{EN}$ AC 51100, which shifted down to $629.1{ }^{\circ} \mathrm{C}$ for $\mathrm{EN}$ AC 51300 alloy. As is evident, for EN AC 51300 the dendrite nucleation temperature increased by approx. $4{ }^{\circ} \mathrm{C}$ with increasing cooling rate. It could be also seen that increasing cooling rate for EN AC 51100 alloy does not provide significant changes in nucleation temperature. The increasing nucleation temperature allows new crystals to 
Table 4 Influence of cooling rate and magnesium content on temperature at dendrite coherency point and fraction solid of investigated magnesium alloys

\begin{tabular}{|c|c|c|c|c|}
\hline \multirow[t]{2}{*}{ Cooling rate $/{ }^{\circ} \mathrm{C} \mathrm{s}^{-1}$} & \multicolumn{2}{|l|}{0.5} & \multicolumn{2}{|l|}{0.9} \\
\hline & $\mathrm{DCP} /{ }^{\circ} \mathrm{C}$ & Fraction solid $/ \%$ & $\mathrm{DCP} /{ }^{\circ} \mathrm{C}$ & $\mathrm{FS} / \%$ \\
\hline EN AC 51100 & 638.47 & 2.8 & 637.71 & 4.1 \\
\hline EN AC 51300 & 626.51 & 3.7 & 623.81 & 8.4 \\
\hline
\end{tabular}

form ahead of solidification, which means there are more nuclei with less potential for growth, and thus effective grain refinement should be expected [14].

The next characteristic points on the crystallisation curves were observed at 638.0 and $625.2{ }^{\circ} \mathrm{C}$, respectively. This event is the $\alpha$-Al dendrite minimum (undercooling) temperature $\left(T_{\mathrm{MIN}}^{\alpha \mathrm{DEN}}\right)$ (point 2$)$, which defines a situation where the nucleated dendrites have grown to such a degree that the liberated latent heat of fusion balances the heat removed from the test sample. The $T_{\mathrm{MIN}}^{\alpha \mathrm{DEN}}$ as the local minimum is defined by the point at which the first derivative crosses the zero line $(\mathrm{d} T / \mathrm{d} t=0)$. It can be noted that increasing cooling rate does not provide significant changes in $T_{\mathrm{MIN}}^{\alpha \mathrm{DEN}}$. Point 3 is the point in which produced $\alpha$ dendrites in liquid melt become coherent $\left(T_{\mathrm{DCP}}^{\alpha \mathrm{DEN}}\right)$. In this point, the second derivative of the cooling curve intersects the zero line (Fig. 6). After passing this point $\left(T_{\mathrm{DCP}}^{\alpha \mathrm{DEN}}\right)$, the melt temperature increases to a steady state growth temperature $\left(T_{\mathrm{G}}^{\alpha \mathrm{DEN}}\right)$ (point 4). The $T_{\mathrm{G}}^{\alpha \mathrm{DEN}}$ matches to the second zero point on the first derivative curve $(\mathrm{d} T / \mathrm{d} t=0)$ following the start of nucleation $(\mathrm{d} T / \mathrm{d} t=0)$. After formation of primary aluminium grains, providing that the concentration of $\mathrm{Si}$ is sufficient, the binary eutectic $\mathrm{Al}+\mathrm{Mg}_{2} \mathrm{Si}$ is formed in the range of temperatures from 544 to $574{ }^{\circ} \mathrm{C}$ (point 5). In fact, in the increasing a cooling rate, the $T_{\mathrm{E}\left(\mathrm{Al}+\mathrm{Mg}_{2} \mathrm{Si}\right)}$ decreased by 3 and $6{ }^{\circ} \mathrm{C}$, respectively. Points 6 correspond to the $\beta-\mathrm{Al}_{3} \mathrm{Mg}_{2}$ eutectic nucleation temperature and the $\beta$ phase eutectic growth. At this point, the $\beta-\mathrm{Al}_{3} \mathrm{Mg}_{2}$ phase starts to form on grain boundaries that could be observed at $563.1{ }^{\circ} \mathrm{C}$ in an alloy that consists of $3 \% \mathrm{Mg}$ and at $436.3{ }^{\circ} \mathrm{C}$ in an alloy that has about $5 \% \mathrm{Mg}$. It could also be seen that increasing cooling rate for examined aluminium alloys, eutectic nucleation temperature $T_{\mathrm{E}\left(\mathrm{Al}+\mathrm{Al}_{3} \mathrm{Mg}_{2}\right)}$ slightly decreased approx. $2{ }^{\circ} \mathrm{C}$. Last point (no. 7) observed on the crystallisation curve is solidus temperature that was observed at $520.1^{\circ} \mathrm{C}$ for $\mathrm{EN}$ AC 51100 alloy and at $416.7^{\circ} \mathrm{C}$ for EN AC 51300 alloy. In fact, in the increasing cooling rate, the solidification range increased approx. $9{ }^{\circ} \mathrm{C}$ for both analysed alloys. This shows that the widening of the crystallisation range can give advantages to semi-solid metal casting (SSM) such as thixocasting, rheocasting or thixomolding; however, it does increase the occurrence of casting defects such as macrosegregation, hot tearing and shrinkage and gas porosity in

Table 5 Results of hardness measurement of EN AC 51100 alloy in as-cast state and after heat treatment

\begin{tabular}{|c|c|c|c|c|c|c|}
\hline \multirow[t]{2}{*}{ Temperature $/{ }^{\circ} \mathrm{C}$} & \multirow{2}{*}{$\begin{array}{l}\text { Solution treatment } \\
\text { time } / \mathrm{h}\end{array}$} & \multirow{2}{*}{$\begin{array}{l}\text { Hardness (as } \\
\text { cast)/HRF }\end{array}$} & \multirow{2}{*}{$\begin{array}{l}\text { Hardness } \\
\text { (solution treated)/HRF }\end{array}$} & \multicolumn{3}{|c|}{ Hardness (ageing $160^{\circ} \mathrm{C}$ )/HRF } \\
\hline & & & & $4 \mathrm{~h}$ & $8 \mathrm{~h}$ & $12 \mathrm{~h}$ \\
\hline \multirow[t]{2}{*}{580} & 8 & 47 & 44.6 & 64.5 & 64.8 & 66.8 \\
\hline & 12 & & 46.0 & 58.1 & 65.3 & 64.8 \\
\hline \multirow[t]{2}{*}{560} & 8 & & 44.5 & 48.1 & 58.4 & 53.4 \\
\hline & 12 & & 45.0 & 47.7 & 58.3 & 61.3 \\
\hline \multirow[t]{2}{*}{540} & 8 & & 47.3 & 46.5 & 50.6 & 48.3 \\
\hline & 12 & & 46.2 & 46.3 & 55.4 & 55.1 \\
\hline
\end{tabular}

Table 6 Results of hardness measurement of EN AC 51300 alloy in as-cast state and after heat treatment

\begin{tabular}{|c|c|c|c|c|c|c|}
\hline \multirow[t]{2}{*}{ Temperature $/{ }^{\circ} \mathrm{C}$} & \multirow{2}{*}{$\begin{array}{l}\text { Solution treatment } \\
\text { time } / \mathrm{h}\end{array}$} & \multirow{2}{*}{$\begin{array}{l}\text { Hardness (as } \\
\text { cast)/HRF }\end{array}$} & \multirow{2}{*}{$\begin{array}{l}\text { Hardness } \\
\text { (solution treated)/HRF }\end{array}$} & \multicolumn{3}{|c|}{ Hardness (ageing $160^{\circ} \mathrm{C}$ )/HRF } \\
\hline & & & & $4 \mathrm{~h}$ & $8 \mathrm{~h}$ & $12 \mathrm{~h}$ \\
\hline \multirow[t]{2}{*}{560} & 8 & 66 & 67.8 & 70.7 & 69.7 & 71.6 \\
\hline & 12 & & 65.9 & 73.4 & 75.4 & 74.5 \\
\hline \multirow[t]{2}{*}{540} & 8 & & 68.7 & 66.6 & 66.4 & 66.7 \\
\hline & 12 & & 67.7 & 68.0 & 71.0 & 71.2 \\
\hline \multirow[t]{2}{*}{520} & 8 & & 66.4 & 70.0 & 67.6 & 69.3 \\
\hline & 12 & & 68.4 & 66.1 & 67.1 & 68.8 \\
\hline
\end{tabular}



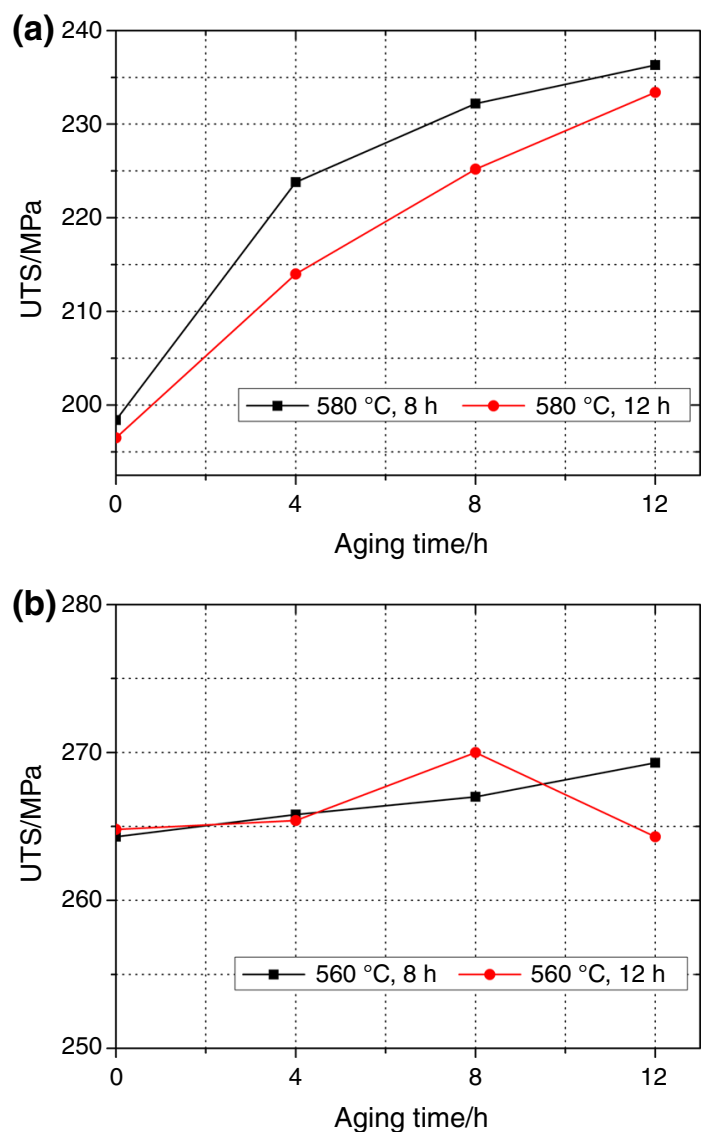

Fig. 7 The influence of the solution treatment and ageing time on tensile strength of a EN AC 51100, b EN AC 51300 alloys

conventional casting. Local deviations from equilibrium result in micro-segregation and eventually in the shift of local equilibrium to the concentrations where new phases are formed.
The second derivative of the cooling curve was used to determine the dendrite coherency point (Fig. 6). The first minimum value of the second derivative of the cooling rate is defined as the DCP, which indicates the transition from liquid to a liquid-solid state. After passing this point, dendrites continued to grow and become thicker with further melt cooling.

The changes of the temperature at dendrite coherency point and the solid fraction corresponding to the dendrite coherency $\left(f_{\mathrm{DCP}}\right)$ as a function of $\mathrm{Mg}$ content and cooling rate are presented in Table 4. It can be seen that fraction solid of primary $\mathrm{Al}$ dendrite coherency point increased from 2.8 to $3.7 \%$ with increasing $\mathrm{Mg}$ content and increased for EN AC 51100 from 2.8 to $4.1 \%$ and increased for EN AC 51300 from 3.7 to $8.4 \%$ with increasing cooling rate. For both analysed series of aluminium alloys can be observed that the increasing cooling rate caused decreases in the temperature at dendrite coherency point from 638.47 to $637.71{ }^{\circ} \mathrm{C}$ for $\mathrm{EN}$ AC 51100 , and from 626.51 to $623.81{ }^{\circ} \mathrm{C}$ for EN AC 51300. In other words, the coherency parameters exhibit that grain refinement reduces the dendrite coherency temperature and can delay dendrite coherency. The DCP has a direct correlation with fluidity; if DCP is delayed, greater fluidity will be achieved. In summary, the investigation of DCP formation by way of TDA shows that the dendrite becomes coherent later with a higher cooling rate and with higher concentration of $\mathrm{Mg}$.

\section{Mechanical properties}

Based on the hardness measurement results of EN AC 51100 and EN AC 51300 alloy that are given in Tables 5 and 6 , it was found that increased magnesium content

Table 7 Tensile properties of EN AC 51100 alloy after precipitation treatment

\begin{tabular}{llllr}
\hline Condition & UTS/MPa & A/\% & Condition & UTS/MPa \\
\hline Solution treated $580{ }^{\circ} \mathrm{C}, 8 \mathrm{~h}$ & 198.4 & 35.8 & Solution treated, $580{ }^{\circ} \mathrm{C} 12 \mathrm{~h}$ & 196.5 \\
Aged $4 \mathrm{~h}, 160^{\circ} \mathrm{C}$ & 223.8 & 29.8 & Aged $4 \mathrm{~h}, 160{ }^{\circ} \mathrm{C}$ & 30.8 \\
Aged $8 \mathrm{~h}, 160{ }^{\circ} \mathrm{C}$ & 232.2 & 25.1 & Aged $8 \mathrm{~h}, 160{ }^{\circ} \mathrm{C}$ & 214.0 \\
Aged $12 \mathrm{~h}, 160{ }^{\circ} \mathrm{C}$ & 236.32 & 25.7 & Aged $12 \mathrm{~h}, 160{ }^{\circ} \mathrm{C}$ & 225.2 \\
\hline
\end{tabular}

Table 8 Tensile properties of EN AC 51300 alloy after precipitation treatment

\begin{tabular}{llllr}
\hline Condition & UTS/MPa & A/\% & Condition & UTS/MPa \\
\hline Solution treated $560^{\circ} \mathrm{C}, 8 \mathrm{~h}$ & 264.3 & 28.3 & Solution treated $560{ }^{\circ} \mathrm{C}, 12 \mathrm{~h}$ & 264.8 \\
Aged $4 \mathrm{~h}, 160^{\circ} \mathrm{C}$ & 265.8 & 32.5 & Aged $4 \mathrm{~h}, 160{ }^{\circ} \mathrm{C}$ & 30.3 \\
Aged $8 \mathrm{~h}, 160{ }^{\circ} \mathrm{C}$ & 267.0 & 34.4 & Aged $8 \mathrm{~h}, 160{ }^{\circ} \mathrm{C}$ & 34.0 \\
Aged $12 \mathrm{~h}, 160{ }^{\circ} \mathrm{C}$ & 269.3 & 30.5 & Aged $12 \mathrm{~h}, 160{ }^{\circ} \mathrm{C}$ & 265.4 \\
\hline
\end{tabular}


influences on the hardness of the alloys which is a result of solid solution hardening. To found most favourable conditions of heat treatment process of investigated alloys, a series of experiments were conducted.

The analysis of data obtained from hardness measurement allows judging that EN AC 51100 alloy has highest ageing potential. As it could be observed after solutionising from temperature $580{ }^{\circ} \mathrm{C}$, there is a significant increase in hardness even after $4 \mathrm{~h}$ of artificial ageing. Further quench ageing results in a subsequent small increase in hardness, and after $12 \mathrm{~h}$ of artificial ageing the material exhibits the highest hardness. Lower temperatures of solid solution treatment do not allow obtaining such a significant increase in hardness, but it can be seen that after quenching from temperature $560{ }^{\circ} \mathrm{C}$ and ageing through $12 \mathrm{~h}$ it is possible to get similar results as earlier. During precipitation treatment of EN AC 51300 alloy, an only small increase in hardness was observed. It could be caused by too short solution treatment time that did not allow the full solution of $\mathrm{Mg}$ in a matrix of the alloy and subsequent precipitation from solid solution when the alloy was artificially aged. As it is presented in Table 6, solution treatment from temperature $560{ }^{\circ} \mathrm{C}$ and subsequent ageing for $12 \mathrm{~h}$ at $160{ }^{\circ} \mathrm{C}$ cause the highest increase in hardness about $14 \%$ in comparison with as-cast state. Quenching from lower temperature results in obtaining considerably lower hardness independent of ageing time that affords conclusion that those heat treatments are not economical because they do not permit to achieving a significant increase in material properties.

To characterise ductility and tensile strength of investigated aluminium alloys after heat treatment, static tensile tests were carried out. Hardness measurements that were taken earlier were used to choose the most beneficial type of heat treatment. For the EN AC 51100 alloy, the tensile tests were carried on samples that were quenched at $580{ }^{\circ} \mathrm{C}$ and, respectively, for EN AC 51300 alloy the temperature of quenching was at $560{ }^{\circ} \mathrm{C}$. Based on the results obtained from static tensile tests of examined alloys, an increase in tensile strength was observed (Table 7). The influence of a solution treatment and ageing time is shown in Fig. 7. As it can be seen the artificial ageing characteristics demonstrating the changes of tensile strength are comparative with hardness measurements obtained earlier. As it was expected the highest tensile strength exhibits alloy that contains $5 \%$ magnesium; however, highest ageing potential presents EN AC 51100 alloy. The increase in tensile strength after $12 \mathrm{~h}$ of artificial ageing is approximately $20 \%$ in comparison with solution-treated specimen. It is also demonstrated that during artificial ageing there is an only small decrease in the ductility of the material. Table 8 also shows that during artificial ageing of EN AC 51300 alloy there are no significant changes in tensile strength. It could be compared to results obtained from hardness measurements where was observed only a small increase in hardness of this alloy. It could be also seen that artificial ageing of EN AC 51300 alloy does not provide significant changes in the ductility of the material. It could also be seen that EN AC 51300 alloy after precipitation treatment exhibits higher ductility than after solution treatment.

\section{Conclusions}

The major conclusions drawn from the study are as follows:

1. Structure examinations of presented aluminium alloys confirm the presence of phases that influence on the hardness of the material. It was also observed that many of precipitated phases during precipitation treatment are considerably lower in comparison with as-cast state that certifies that a lot of $\mathrm{Mg}$ stays in solid solution and during artificial ageing precipitated uniformly in the core material.

2. The higher cooling rate causes a decrease of solidus temperature in investigated alloys, resulting in an extension of the crystallisation range approx. $9{ }^{\circ} \mathrm{C}$ for both analysed alloys.

3. A solid fraction at the dendrite coherency point determined from the second derivative of cooling curve increases with increasing $\mathrm{Mg}$ content and cooling rate.

4. Despite micro-additions presence, it was not seen any changes in crystallisation curve that certify forming phases that contain $\mathrm{Si}$ or $\mathrm{Cu}$ which is caused by too little mass fraction of these additions in investigated alloys.

5. As a result of conducted heat treatment process with different parameters of temperature and time and based on the hardness measurement best types of precipitation treatment were selected to carry out tensile tests. It has been proven that heat treatment has a significant effect on the hardness and tensile strength EN AC 51100 alloy, but results in a decrease in ductility of the material; however, precipitation treatment of EN AC 51300 alloy resulted in only a slight improvement in mechanical properties that could be caused by too short time of solution treatment.

6. Based on the investigation results presented above, optimum heat treatment conditions were selected. For the EN AC 51100 aluminium alloy solution treatment temperature and time were $580{ }^{\circ} \mathrm{C}$ and $8 \mathrm{~h}$ with artificial ageing for $8 \mathrm{~h}$ at $160{ }^{\circ} \mathrm{C}$; however, in the case of the EN AC 51300 solution treatment 
temperature and time were $560{ }^{\circ} \mathrm{C}$ and $12 \mathrm{~h}$ with ageing treatment for $8 \mathrm{~h}$ at $160{ }^{\circ} \mathrm{C}$.

7. The thermal analysis of the heating cycle permits the development of an optimum two- and/or multi-step solution treatment capable of improving the dissolution of the soluble phases and which results in achieving significantly higher mechanical characteristics in slowly solidified section of the automotive components.

Acknowledgements This publication was financed by the Ministry of Science and Higher Education of Poland as the statutory financial grant of the Faculty of Mechanical Engineering SUT.

Open Access This article is distributed under the terms of the Creative Commons Attribution 4.0 International License (http://crea tivecommons.org/licenses/by/4.0/), which permits unrestricted use, distribution, and reproduction in any medium, provided you give appropriate credit to the original author(s) and the source, provide a link to the Creative Commons license, and indicate if changes were made.

\section{References}

1. Canales AA, Carrera E, Talamantes-Silva J, Valtierra S, Colás R. Mechanical properties in as-cast and heat treated $\mathrm{Al}-\mathrm{Si}-\mathrm{Cu}$ alloys. Int J Microstruct Mater Prop. 2012;7(4):281-300.

2. Jayalakshmi S, Dezhi Q, Sankaranarayanan S, Gupta M. Microstructure and mechanical properties of $\mathrm{Mg}-\mathrm{Al}$ alloys with in situ $\mathrm{Al} 4 \mathrm{C} 3$ phase synthesised by $\mathrm{CO}_{2}$ incorporation during liquid state processing. Int J Microstruct Mater Prop. 2013;8(4/ 5):283-98.

3. Kaygisiz Y, Marasli N. Microstructural, mechanical and electrical characterization of directionally solidified $\mathrm{Al}-\mathrm{Si}-\mathrm{Mg}$ eutectic alloy. J Alloys Compd. 2014;618:197-203.

4. Shu-qing Y, Xing-fu L. The effect of Si morphology on the microstructure and wear property of ZA48 alloy. Int J Microstruct Mater Prop. 2014;9(1):88-96.

5. Luna I, Molinar H, Roman M, Bocardo J, Trejo M. Improvement of the tensile properties of an $\mathrm{Al}-\mathrm{Si}-\mathrm{Cu}-\mathrm{Mg}$ aluminium industrial alloy by using multi stage solution heat treatments. Mater Sci Eng A Struct. 2013;561:1-6.

6. Shokuhfar A, Nejadseyfi O. A comparison of the effects of severe plastic deformation and heat treatment on the tensile properties and impact toughness of aluminium alloy 6061. Mater Sci Eng A Struct. 2014;594:140-8.
7. Krupiński M, Labisz K, Tański T, Krupińska B, Król M, PolokRubiniec $\mathrm{M}$. Influence of $\mathrm{Mg}$ addition on crystallisation kinetics and structure of the $\mathrm{Zn}-\mathrm{Al}-\mathrm{Cu}$ alloy. Arch Metall Mater. 2016;61(2):785-90. doi:10.1515/amm-2016-0132.

8. Król M, Tański T, Matula G, Snopiński P, Tomiczek AE. Analysis of crystallisation process of cast magnesium alloys based on thermal derivative analysis. Arch Metall Mater. 2015;60(4):2993-3000. doi:10.1515/amm-2015-0478.

9. Xia S, Ma M, Zhang J, Wang W, Liu W. Effect of heating rate on the microstructure, texture and tensile properties of continuous cast AA 5083 aluminium alloy. Mater Sci Eng A. 2014;609: $168-76$.

10. Krupińska B, Krupiński M, Labisz K, Rdzawski Z, Tański T. Additives and thermal treatment influence on microstructure of nonferrous alloys. J Therm Anal Calorim. 2015;3:1573-83. doi:10.1007/s10973-015-4497-0.

11. Tański T, Pakieła W, Janicki D, Tomiczek B, Król M. Properties of the aluminium alloy EN AC 51100 after the laser surface treatment. Arch Metall Mater. 2016;61(1):199-204. doi:10.1515/ amm-2016-0035.

12. Król M, Tański T, Sitek W. Thermal analysis and microstructural characterization of $\mathrm{Mg}-\mathrm{Al}-\mathrm{Zn}$ system alloys. In: IOP conference series: materials science and engineering, vol. 95; 2015. p. 012006. doi:10.1088/1757-899X/95/1/012006.

13. Method and Apparatus for Universal Metallurgical Simulation and Analysis-United States Patent, Patent No.: US 7,354,491 B2, Date of Patent: 8 April 2008.

14. Farahany S, Idris MH, Ourdjini A, Faris F, Ghandvar H. Evaluation of the effect of grain refiners on the solidification characteristics of an Sr-modified ADC12 die-casting alloy by cooling curve thermal analysis. J Therm Anal Calorim. 2015;119(3): 1593-601.

15. Hamana D, Baziz L, Bouchear M. Kinetics and mechanism of formation and transformation of metastable $\beta^{\prime}$-phase in $\mathrm{Al}-\mathrm{Mg}$ alloys. Mater Chem Phys. 2004;84(1):112-9.

16. Starink MJ, Zahra AM. $\beta^{\prime}$ and $\beta$ precipitation in an $\mathrm{Al}-\mathrm{Mg}$ alloy studied by DSC and TEM. Acta Mater. 1998;46(10):3381-97.

17. Venkatachalam $P$, Ravisankar B, Kumaran S. Microstructure and mechanical properties of $2014 \mathrm{Al}$ alloy processed by equal channel angular pressing (ECAP). Int J Microstruct Mater Prop. 2010;5(1):88-100.

18. Žagar S, Grum J. Residual stress, fatigue and electrical conductivity analysis after shot peening of aluminium alloy AlZn5.5MgCu. Int J Microstruct Mater Prop. 2013;8(6):447-61.

19. Belov NA, Eskin DG, Aksenov AA. Multicomponent phase diagrams: applications for commercial aluminum alloys. Amsterdam: Elsevier Ltd.; 2005.

20. Eskin DG. Physical metallurgy of direct chill casting of aluminum alloys. London: Taylor\&Francis Group; 2008.

21. Snopiński P, Tański T, Labisz K, Rusz S, Jonsta P, Król M. Wrought aluminium-magnesium alloys subjected to SPD processing. Int J Mater Res. 2016;107:1-9. doi:10.3139/146.111383. 